\title{
DESIGN CONCEPT OF LUNAR ROVER FOR THE MOON GEOLOGICAL EXPLORATION
}

\author{
Andrey Vasiliev ${ }^{\mathrm{a}}$, Igor Dalyaev ${ }^{\mathrm{a}}$, Evgeny Slyuta ${ }^{\mathrm{b}}$
}

\begin{abstract}
${ }^{\text {a} R u s s i a n ~ S t a t e ~ S c i e n t i f i c ~ C e n t e r ~ f o r ~ R o b o t i c s ~ a n d ~ T e c h n i c a l ~ C y b e r n e t i c s ~(R T C), ~ S a i n t-P e t e r s b u r g, ~ R u s s i a ~}$ ${ }^{b}$ Vernadsky Institute of Geochemistry and Analytical Chemistry of Russian Academy of Sciences, Moscow, Russia
\end{abstract}
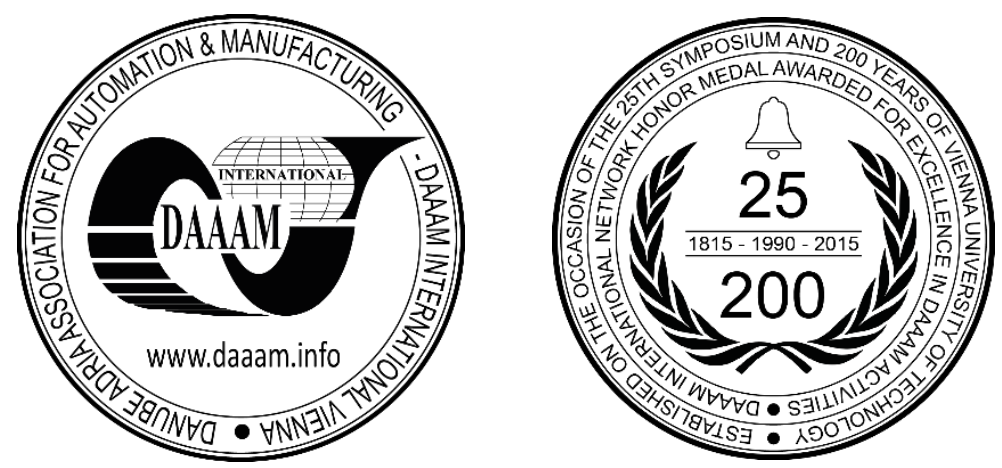

This Publication has to be referred as: Vasiliev, A[ndrey]; Dalyaev, I[gor] \& Slyuta, E[vgeny] (2017). Design Concept Lunar Rover for the Moon Geological Exploration, Proceedings of the 28th DAAAM International Symposium, pp.07800786, B. Katalinic (Ed.), Published by DAAAM International, ISBN 978-3-902734-11-2, ISSN 1726-9679, Vienna, Austria

DOI: $10.2507 / 28$ th.daaam.proceedings.110

\begin{abstract}
The paper discusses the current results of mobile robotic system «Robot-Geologist» development. The robot is intended to maintain geological exploration on the surface of the Moon. Distinctive features of the project in comparison with the known planetary rover projects comprise: superior length of the estimated research route up to $500 \mathrm{~km}$; an autonomous control system capable of moving from one point of scientific interest to the other; a wide range of scientific equipment and an extensive program of research, including lunar surface sampling along with drilling and investigation of wells. The key feature of the "Robot-Geologist" is the ability to transport samples in the course of the expedition and upload them to returnable spacecraft. The paper presents a description of the proposed robot concept as a result of the project development.
\end{abstract}

Keywords: Mobile robotic system; geological exploration; Moon research; moon (lunar) rover; drilling rig; manipulation system; ground sampling; robot-geologist

\section{Introduction}

Research of the Moon is one of the immediate tasks for space exploration. The moon is the largest celestial body close to Earth, a source of important natural resources, a unique base for astrophysical observations and other scientific research, and in the long term it can be considered as a reference point for long-range manned space missions.

The first stage of the development of the moon should be research on its surface involving a network of stationary and self-propelled scientific stations [1]. The thematic geological survey and preliminary geological exploration constitute together an important and necessary stage in the development of the Moon, which should provide not only extensive scientific information, but also provide the information necessary for the optimal location determination of a long-term or periodically inhabited lunar base, the deployment of a primary industrial infrastructure and the preparation for future manned lunar missions. 
The use of a stationary research apparatus on the lunar surface is advisable in areas characterized by relatively stable geological properties. However, full-scale studies in areas where there are a variety of complexes of rocks of different ages, genesis, composition and spectral classes are practically impossible without the use of a mobile apparatus. The estimated route variations for such studies, the length of which is up to 400-500 km, were developed by scientists of Vernadsky Institute of Geochemistry and Analytical Chemistry (Moscow) [2]. According to its geological structure, the region of Mons Rümker in the northwestern part of the Oceanus Procellarum is one of the primary landing sites and research areas for the mobile research apparatus [1,2]. The scheme of this route is shown in Fig.1. The main geological studies are expected to be carried out by the methods of well drilling with sampling of stratified cores of regolith, and by collecting small samples (up to 50-100 g) of the surface layer of regolith and stones.
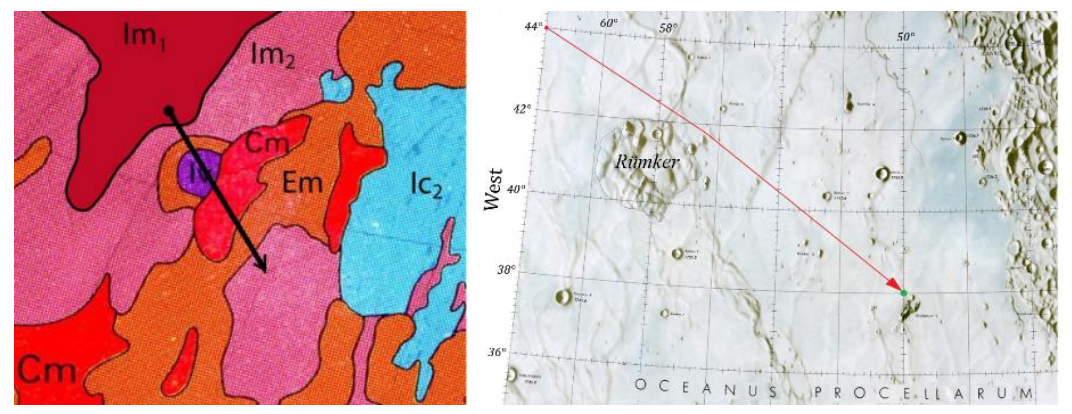

Fig. 1. Geologic map of Mons Rümker region [3] and schematic representation of the route (the arrow length is about 400 km): Im1 - Lower Imbrian Series basalts; Im2 - Upper Imbrian Series basalts; Em - Eratosthenian System basalts;

$\mathrm{Cm}$ - Copernican System basalts; Iv - volcanic province; Ic2 - crater material from Mare Imbrium basin

In connection with the foregoing, the first and foremost task is to create a new generation of automatic research apparatus - the Mobile Robotic System (MRS) for geological survey, equipped with a drilling rig, a manipulation system and a set of scientific tools.

The purpose of this project is the preliminary development of the design appearance of such an apparatus under the conventional name "Robot-Geologist". The term "design appearance" here means not only the overall technical appearance of the whole system and basic technical solutions for its composition and design, but also scenarios of the MRS activity.

The tasks for the MRS, set by the skilled geochemists, are as follows:

- locomotion along the route up to $400-500 \mathrm{~km}$;

- drilling of several wells up to 3-6 m deep with sampling of continuous cores of lunar regolith while maintaining their complete stratification;

- surface soil sampling with a certain periodicity;

- carrying out a wide range of scientific research (gravimetry, magnetometry, spectrometry, active and passive seismic studies, etc.);

- deployment of a long-term monitoring automatic scientific research station (ASRS) near one of the wells;

- delivering and re-laying of collected samples with a total mass of up to $100 \mathrm{~kg}$ into the automatic lunar transport spacecraft, waiting for the MRS at one of the intermediate points of the route or at its final point.

The project is being developed by the Russian State Scientific Center for Robotics and Technical Cybernetics (RTC) in St.-Petersburg with the support of Russian Space Agency in accordance with the initiative and recommendations of the Vernadsky Institute of Geochemistry and Analytical Chemistry of Russian Academy of Sciences.

\section{Prototypes}

To meet the set of requirements, the MRS has a number of unique features. The review of the stationary and selfpropelled apparatus equipped with drilling rigs for conducting studies on the surface of other celestial bodies that were created earlier or are being developed at present [4-8], shows that there are no analogues of the MRS. Current research in the world in similar areas usually involve drilling of shallow wells without maintaining stratification of the core samples, short-term missions that cover geologically small areas (i.e., limited in length and duration of research), do not involve the delivery of collected samples to the Earth [6,7]. Fig. 2 shows some of the examples of already employed and currently developed systems for drilling in space.

The developed concept of geological research on the Moon's surface by means of the lumokhod "Robot-Geologist" takes into account the experience of all the previous lunar missions, such as studies by means of Soviet scientific stations "Luna" and american "Apollo" missions. 


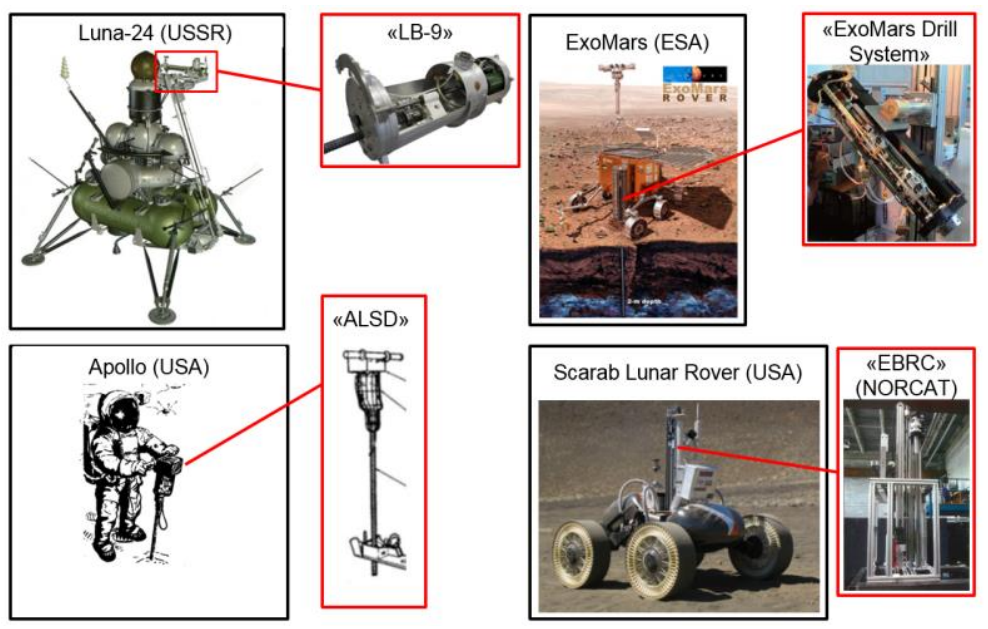

Fig. 2. Examples of drilling systems for the Moon and the Mars

\section{MRS concept}

The MRS concept aggregates the development of basic technical solutions for all the rover subsystems, the general technical design of the MRS and the development of scenarios for scientific tasks performing.

The fundamental difference between MRS and all previously created planet rovers is the required route length which is more than an order of magnitude greater than the maximum distance traveled by terrestrial mobile vehicles along the surface of another celestial body [5, 9]. The length of the proposed MRS route is not less than $400 \mathrm{~km}$. This fact, combined with the general specificity of the MRS, justifies the desire to simplify the chassis design as much as possible in order to ensure its maximum reliability.

The length of the mission and the unprecedented travel distance also impose special requirements to the MRS control system, which should provide not only remote control mode, but also autonomous locomotion with real-time environment assessment and insurmountable obstacles avoiding [10].

In the course of the project, the MRS design appearance was accomplished. As a result, a three-dimensional computer model of the MRS was developed, that is shown in Fig. 3. The MRS can be represented as two main parts: service systems and payload.

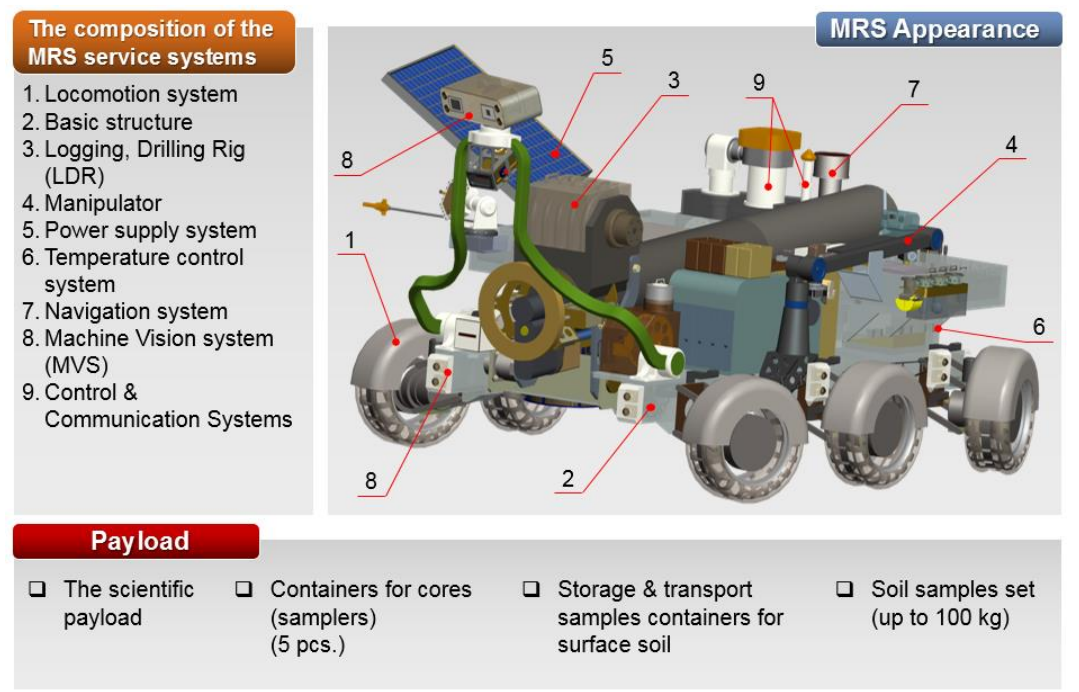

Fig. 3. The Lunokhod «Robot-Geologist» appearance, payload and service systems composition

Service systems comprises (see Fig.3): locomotion system (1); basic structure (2); logging and drilling rig (LDR) (3); manipulation system (4); power supply system (5); thermal control system (6); navigation system (7); machine vision system (MVS) (8); integrated on-board control system and communication system (9).

The payload includes a set of scientific tools, equipment for storing and transporting cores from wells and samples of the surface layer of regolith, as well as the samples themselves with a total mass of up to $100 \mathrm{~kg}$.

The following scientific equipment is situated onboard: 1) scientific navigation devices, including: radio beacon, TVspectrometer, IR-spectrometer, TV-camera for manipulator service area; 2) geophysical research tools, including: set for 
active and passive seismic survey, geological radar, logging device, magnetometer and gravimeter; 3 ) tools for studying the composition of the lunar soil and gases, including: gas analyzer for the study of weakly bound volatiles in lunar regolith and for the study of the lunar atmosphere, gamma-spectrometer and neutron detector; 4) the sampler devices, including: drilling rig and manipulator with cassettes for the collection and storage of core samples and soil samples.

The basic structure of the MRS consists of three main parts: a frame, a hermetical equipment bay and an open body platform for placing autonomously operating scientific equipment to be unloaded during the mission to the lunar surface by means of a manipulator $[11,12]$.

The universal chassis is built on the basis of six identical modules of the motor-wheels. Each module is attached to the MRS frame and contains a wheel, a steering drive, suspension levers and mounting shield.

The MRS design specification is presented in Table 1.

\begin{tabular}{|l|c|c|}
\hline \multicolumn{1}{|c|}{ Parameter } & Unit & Value \\
\hline Mass (without soil samples set) & $\mathrm{kg}$ & 1350 \\
\hline Load capacity of soil samples set & $\mathrm{kg}$ & 100 \\
\hline Chassis mass & $\mathrm{kg}$ & 542 \\
\hline Scientific equipment mass & $\mathrm{kg}$ & 200 \\
\hline Autonomy (time), not less than & $\mathrm{hour}$ & 20 \\
\hline Autonomy (distance), not less than & $\mathrm{km}$ & 40 \\
\hline Maximal obstacle height & $\mathrm{mm}$ & 250 \\
\hline Angle of surface inclination & $\mathrm{grades}$ & 20 \\
\hline $\begin{array}{l}\text { Maximal speed on a flat surface } \\
-\quad \text { in autonomous mode } \\
-\quad \text { in remote control mode }\end{array}$ & $\mathrm{km} / \mathrm{h}$ & 3 \\
\hline Range & $\mathrm{km} / \mathrm{h}$ & 5 \\
\hline Active lifetime & $\mathrm{km}$ & 500 \\
\hline
\end{tabular}

Table 1. The MRS design specification

\section{Logging-Drilling Rig (LDR) composition}

The main and most massive part of the MRS is the LDR. It has a sufficiently large length (up to $4 \mathrm{~m}$ ) and is placed on a lunar rover in a horizontal position.

Such LDR placement was chosen after comparing two ways: a vertical fixed placement (Fig.4a) and a horizontal deployable one (Fig.4b). Both of them have their own advantages and drawbacks. The analytical comparison is presented in Table 2.

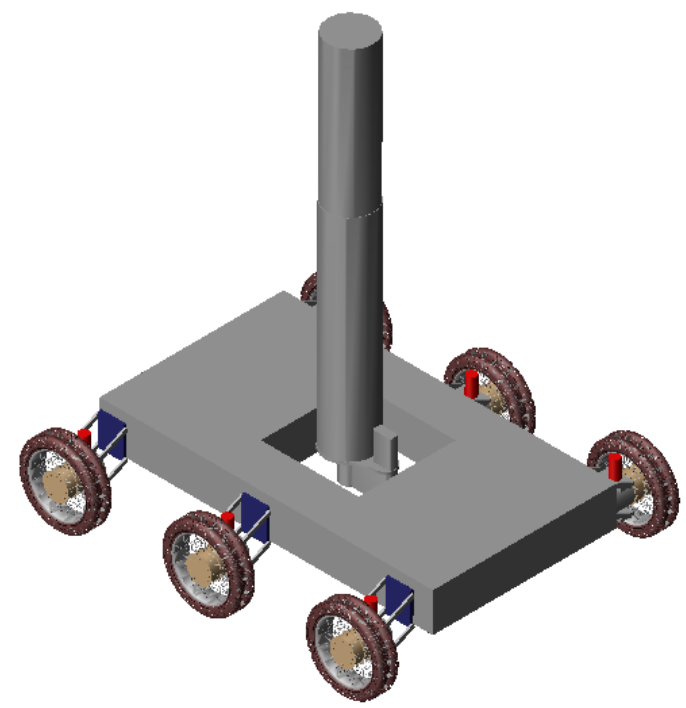

a)

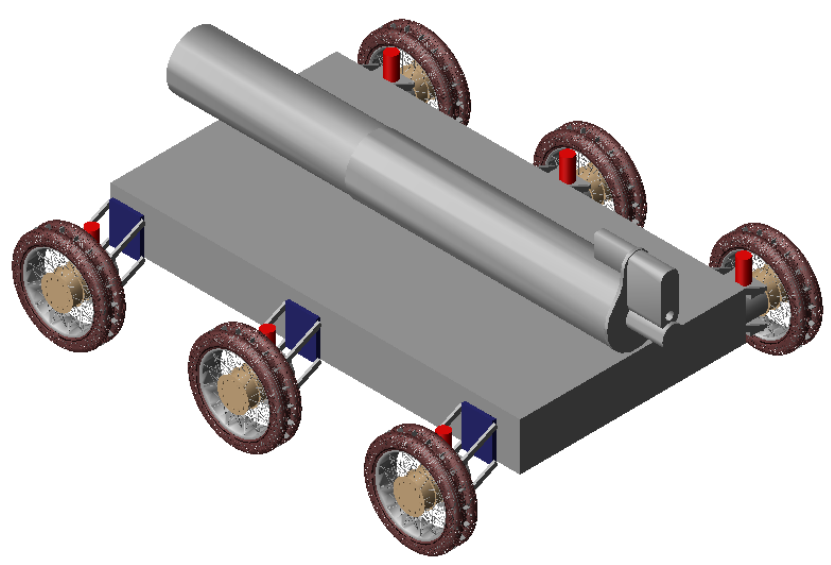

b)

Fig. 4. The schemes of the MRS on-board LDR placement 


\begin{tabular}{|c|c|c|c|c|}
\hline \multirow{2}{*}{ Estimated characteristic } & \multicolumn{4}{|c|}{ Analysis results } \\
\hline & \multicolumn{2}{|l|}{ Scheme on Fig.4a } & \multicolumn{2}{|l|}{ Scheme on Fig.4b } \\
\hline Overall dimensions & $\begin{array}{l}\text { Significant overall height } \\
\text { dimension }\end{array}$ & - & Minimal overall dimensions & + \\
\hline Layout & $\begin{array}{l}\text { The minimal space LDR occupied } \\
\text { on the MRS platform }\end{array}$ & + & $\begin{array}{l}\text { A significant space LDR occupied } \\
\text { on the MRS platform }\end{array}$ & - \\
\hline Design advantages & $\begin{array}{l}\text { Design symmetry. No need for } \\
\text { additional outriggers }\end{array}$ & + & $\begin{array}{l}\text { The minimal height of the center } \\
\text { of gravity of the MRS }\end{array}$ & + \\
\hline Design drawbacks & $\begin{array}{l}\text { High location of the MRS center } \\
\text { of gravity. } \\
\text { Large required service area of the } \\
\text { manipulator (if there is a } \\
\text { requirement to reach the upper } \\
\text { part of the LDR); }\end{array}$ & - & $\begin{array}{l}\text { The MRS center of gravity shifts } \\
\text { forward when the LDR is in the } \\
\text { working position. Additional } \\
\text { outriggers are necessary. }\end{array}$ & - \\
\hline Operational specificities & $\begin{array}{l}\text { Less stable driving over typical } \\
\text { obstacles }\end{array}$ & - & $\begin{array}{l}\text { More stable driving through } \\
\text { typical obstacles }\end{array}$ & + \\
\hline $\begin{array}{l}\text { Possibility of emergency LDR } \\
\text { undocking from the MRS }\end{array}$ & Impossible & - & Possible & + \\
\hline $\begin{array}{l}\text { Placement of MRS in the } \\
\text { transport volume of the launch } \\
\text { spacecraft vehicle }\end{array}$ & Non-rational & - & Relatively compact & + \\
\hline
\end{tabular}

Table 2. The LDR on-board placement comparison

Large dimensions of the LDR predetermined the overall layout of the MRS: the platform is divided into three areas, as shown in Fig.5a: area (I) is reserved for the placement of the equipment bay and the solar battery with its orientation drive; area (II) in the center is for the placement of the LDR; area (III) comprises an open body platform for the scientific equipment along with the manipulation system and other equipment.

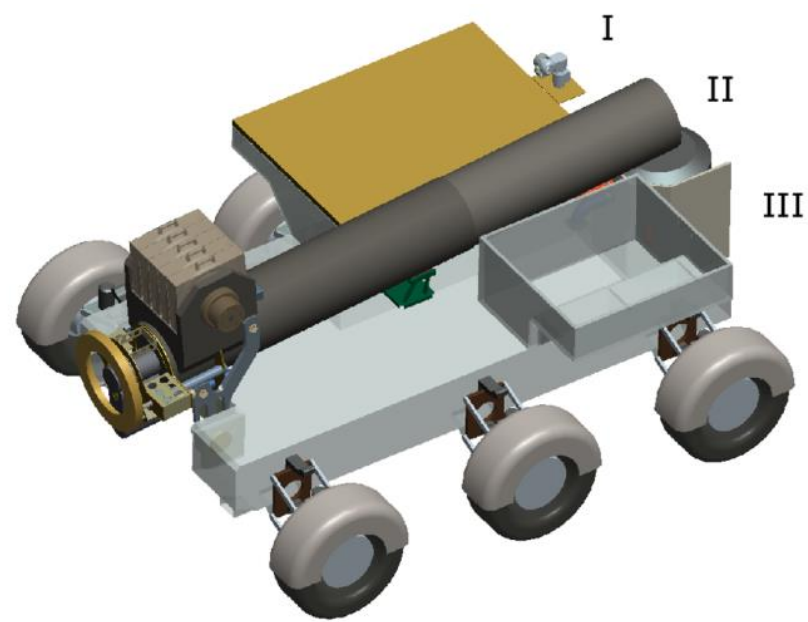

a)

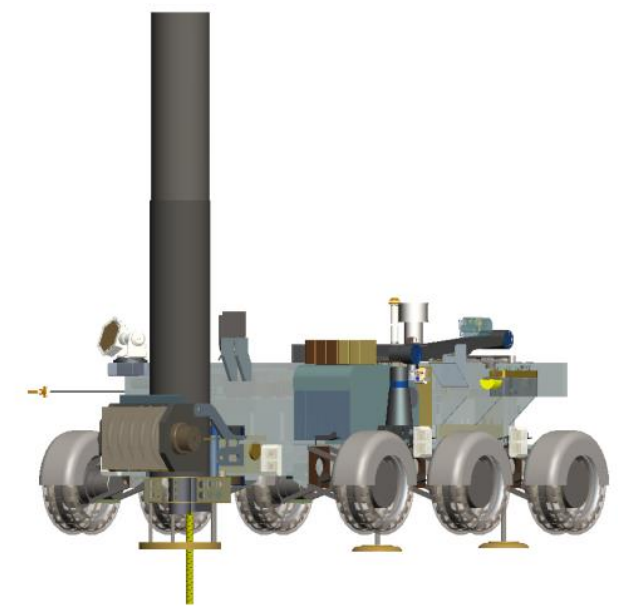

b)

Fig. 5. The LDR on-board placement (a) and the MRS drilling configuration (b)

When drilling, the LDR is being vertically moved, as shown in Fig.5b. At the same time, the MRS rises on three pullout supports: one is located along the axis of the LDR and the other two are located at the rear of the MRS.

The main part of the LDR is an automatic logging-drilling machine, the prototype of which is the LB-10 machine [13]. The LB-10 machine shown in Fig.6a, with a potential drilling depth of up to $15 \mathrm{~m}$, was developed in the USSR as the next generation of the LB-9 machine that was successfully used on the "Luna-24" station.

As a result of considering the MRS drilling scenarios, the design of the LDR was substantially modified. The LDR, as shown in Fig.6b, in addition to the logging-drilling machine (1) includes: a frame (2) with a deployment drive, a clamping mechanism (3), sample containers (4).

The deployment drive serves to transfer the LDR from the transport position to the vertical working one. The clamping mechanism ensures the unloading of the drilling machine tool and acts in conjunction with two retractable supports (outriggers) in the rear part of the MRS. 


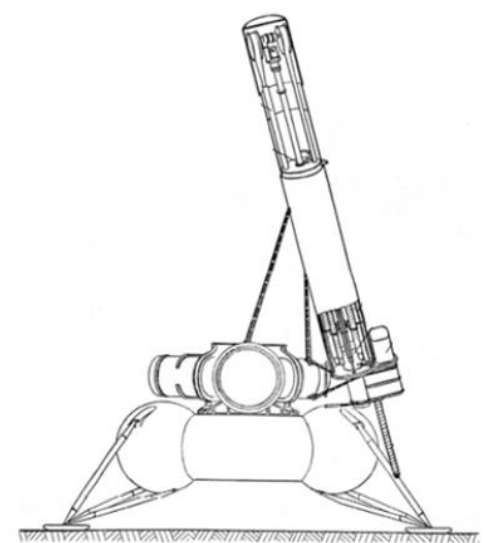

a)

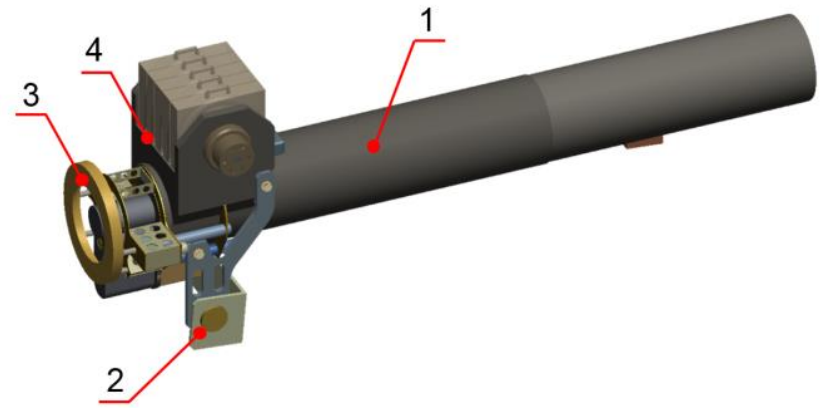

b)

Fig. 6. Drilling rigs: a) LB-10 automatic logging-drilling machine; b) the MRS logging-drilling rig (LDR)

The LDR specification is given in Table 3.

\begin{tabular}{|l|c|c|}
\hline \multicolumn{1}{|c|}{ Parameter } & Unit & Value \\
\hline Drilling depth & $\mathrm{mm}$ & $3000-6000$ \\
\hline Well diameter & $\mathrm{mm}$ & 57 \\
\hline Core diameter & $\mathrm{mm}$ & 32 \\
\hline The drilling tool maximum force & $\mathrm{N}$ & 200 \\
\hline Nominal force of LDR to surface clamping & $\mathrm{N}$ & 1200 \\
\hline Nominal power consumption & $\mathrm{W}$ & 1000 \\
\hline Overall dimensions & $\mathrm{mm}$ & $4000 \times 720 \times 492$ \\
\hline Mass & $\mathrm{kg}$ & 120 \\
\hline
\end{tabular}

Table 3. The LDR specification

The LDR is equipped with detachable containers with the possibility of their capture by the manipulator and transfer onto the returnable automatic transport spacecraft.

\section{Conclusion}

In connection with the developed concept of geological research on the surface of the Moon the first and foremost task is to create a new generation of automatic research apparatus - the Mobile Robotic System (MRS) for geological survey, equipped with a drilling rig, a manipulation system and a set of scientific tools.

To meet the set of requirements, the MRS has a number of unique features. Distinctive features in comparison with the known planetary rovers comprise: superior length of the estimated research route up to $500 \mathrm{~km}$; an autonomous control system capable of moving from one point of scientific interest to the other; a wide range of scientific equipment and an extensive program of research, including lunar surface sampling along with drilling and investigation of wells. The key feature of the MRS is the ability to transport samples in the course of the expedition and upload them to returnable spacecraft.

The project is aimed at the preliminary development of the design appearance of such the MRS under the conventional name "Robot-Geologist". The term "design appearance" here means not only the overall technical appearance of the whole system and basic technical solutions for its composition and design, but also scenarios of the MRS activity.

In the course of the project, the MRS design appearance was accomplished. The project development involved the necessary design work, the calculation of all the main MRS subsystems, MRS activity scenarios development, determination of the design specification and the main technical requirements for the MRS and its subsystems.

The article provides a brief description of the design concept development of a MRS "Robot-Geologist" intended for conducting geological studies on the lunar surface. The crucial and most massive part of the MRS is a logging-drilling rig LDR, the description of which has been given special attention.

LDR composition and MRS on-board placement was accomplished. The main part of the LDR is an automatic logging-drilling machine. Its prototype is the LB-10 machine, which was developed in the USSR as the next generation of the LB-9 machine successfully used on the "Luna-24" scientific research station. As a result of considering the MRS drilling scenarios, the design of the LDR was substantially modified.

Further research is aimed at refining the design of the key subsystems of the MRS, namely: locomotion system, LDR and manipulation system. 


\section{Acknowledgments}

The research is performed in the Russian State Scientific Center for Robotics and Technical Cybernetics (RTC) with the support of Russian Space Agency. Scientific tasks and technologies of geological research on the lunar surface are developed in Vernadsky Institute of Geochemistry and Analytical Chemistry of Russian Academy of Sciences.

\section{References}

[1] Fundamental Space Research (2014), Raykunov, G.G. (Ed.), Book 2, Fismatlit, ISBN: 978-5-9221-1559-9, Moscow, $457 \mathrm{p}$.

[2] Slyuta, E.N.; Vasilev, A.V. \& Dalyaev, I.Yu. (2017). Lunokhod "Robot-Geologist": scientific tasks and technical configuration, Proceedings of 48th Lunar and Planetary Science Conference, March 20-24, 2017, Houston, USA, Available from: http://www.hou.usra.edu/meetings/lpsc2017/pdf/1929.pdf Accessed on: 2017-03-09

[3] Wilhelms, D. E. (1987). The Geologic History of the Moon, United States Government Printing Office, ISBN: 1495919854, Washington, 329 p.

[4] Drilling in Extreme Environments. Penetration and Sampling on Earth and other Planets. (2008). Bar-Cohen, J. \& Zacny, K. (Ed.), WILEY-VCH, ISBN: 978-3-527-40852-8, Germany, 767 p.

[5] Young, A.H. (2007). Lunar and Planetary Rovers. The wheels of Apollo and the Quest for Mars, Springer, Praxis Publishing, ISBN 10: 0-387-30774-5, Germany, 393 p.

[6] Bartlett, P.; Wettergreen, D.; Whittaker, W.L.; et al. (2008). Design of the Scarab Rover for Mobility and Drilling in the Lunar Cold Traps, Proceedings of International Symposium on Artificial Intelligence, Robotics and Automation in Space, Available from: http://www.ri.cmu.edu/pub_files/2009/1/09aiaa.scarab.pdf Accessed: 201706-23

[7] Sanders, G.B.; Barid, R.S.; Rogers K.N.; et al. (2012). RESOLVE. Lunar Ice/Volatile Payload Development and Field Test Status, Presentation to LEAG, October, 24, 2012, Available from: http://www.lpi.usra.edu/meetings/ leag2012/presentations/Sanders.pdf Accessed: 2017-06-23

[8] Krylov, I. (2015). "Yutu" told about the Moon, Available from: http://www.gazeta.ru/science/2015/12/23_a_ 7985801.shtml Accessed: 2017-06-23

[9] Planetokhody (Planet Rovers) (1993), Kemurdzhian, A.L. (ed.), Mashinostroenie, Moscow, 400 p.

[10] Smirnova, E.; Stepanov, D. \& Goryunov, V. (2016). A Technique of Natural Visual Landmarks Detection and Description for Mobile Robot Cognitive Navigation, Proceedings of the 26th DAAAM International Symposium, pp.0905-0911, B. Katalinic (Ed.), Published by DAAAM International, ISBN 978-3-902734-07-5, ISSN 1726-9679, Vienna, Austria, DOI: 10.2507/26th.daaam.proceedings.126, Available from: http://www.daaam.info/Downloads/Pdfs/ proceedings/proceedings_2015/126.pdf Accessed: 2017-06-23

[11] Lopota, A.; Dalyaev, I.; Shardyko, I.; Kuznetcova, E. \& Belezyakov, I. (2016). Means of Robotic Support for OnOrbit Servicing, Proceedings of the 26th DAAAM International Symposium, pp.0865-0870, B. Katalinic (Ed.), Published by DAAAM International, ISBN 978-3-902734-07-5, ISSN 1726-9679, Vienna, Austria, DOI:10.2507/26th.daaam.proceedings.120, Available from: http://www.daaam.info/Downloads/Pdfs/proceedings/ proceedings_2015/120.pdf Accessed: 2017-06-23

[12] Isaenko, S.; Sochivko, O.; Shardyko, I. \& Titov, V. (2016). Simulation of Manipulator as a Part of Space Robotic System Weightlessness Device, Proceedings of the 26th DAAAM International Symposium, pp.0554-0561, B. Katalinic (Ed.), Published by DAAAM International, ISBN 978-3-902734-07-5, ISSN 1726-9679, Vienna, Austria, DOI: 10.2507/26th.daaam.proceedings.076, Available from: http://www.daaam.info/Downloads/Pdfs/proceedings/proceedings_ 2015/076.pdf Accessed: 2017-06-23

[13] The Moon - a step towards the technologies of the solar system development (2011), Legostaev, V.P. \& Lopota V.A. (ed.), RSC Energia, ISBN: 978-5-91820-046-9, Moscow, 584 p. 